\title{
Optic disc changes following trabeculectomy: longitudinal and localisation of change
}

\author{
Aachal Kotecha, Dilani Siriwardena, Frederick W Fitzke, Roger A Hitchings, Peng T Khaw
}

\begin{abstract}
Aims-To determine whether there were any changes in the optic disc at 2 years after trabeculectomy. To determine the factors that most influenced change and whether change was localised to any region of the optic disc.
\end{abstract}

Methods-95 patients undergoing routine trabeculectomy as part of the ongoing Moorfields/MRC 5-fluorouracil trial were recruited into the study. Eyes were imaged preoperatively (4 (SD 3) weeks) with the Heidelberg retina tomograph (HRT, Heidelberg Engineering), and at 3 months (SD 2 weeks), 1 year (SD 1 month), and 2 years (SD 1 month) after surgery. Parameters investigated for change were rim area, rim volume, and maximum cup depth. The predefined segment analysis available on the HRT analysis software was used to determine segmental change. Results-The images of 70 patients were analysed. Intraocular pressure reduced from 22.25 (SD 3.76) $\mathrm{mm} \mathrm{Hg}$, at the time of preoperative imaging to 15.27 (SD 4.96) $\mathrm{mm} \mathrm{Hg}$ at 3 months, 14.38 (SD 3.89) $\mathrm{mm}$ $\mathrm{Hg}$ at 1 year, and 13.80 (SD 3.54) $\mathrm{mm} \mathrm{Hg}$ at 2 years after trabeculectomy. An increase in rim area and rim volume was present at all time points after surgery, but was only found to be statistically significant at 2 years after surgery. Maximum depth of cup reduced by month 3 and month 12 , but showed a slight increase at 2 years after surgery, although this was still lower than the preoperative measure. Segmental analysis found a significant change in rim volume in the nasal, inferonasal, superonasal, and superotemporal regions at 2 years after surgery. No significant regional localisation for change was found at any other time point or in any other parameter investigated.

Conclusions-Reversal of disc cupping is present at 2 years after trabeculectomy. The factor most influencing change is reduction of intraocular pressure. Segmental analysis showed that change in rim volume was greatest in the nasal, inferonasal, superonasal and superotemporal regions at 2 years.

(Br F Ophthalmol 2001;85:956-961)
Reversal of optic disc cupping following intraocular pressure reduction is a well known phenomenon $^{12-10}$ and changes seen in juvenile glaucomas are more pronounced than those found in adult patients. ${ }^{11-13}$ Examination of stereodisc photographs ${ }^{1314}$ have shown that changes do occur in adults, but of a smaller magnitude than in children. The advent of more sophisticated fundal imaging techniques means that these changes are now more easily quantifiable. Many studies have been done to quantify the degree of optic disc change following pressure reduction in experimental models, ${ }^{6}{ }^{15-18}$ and in human subjects following pressure reduction by medical and surgical treatments ${ }^{31920}$ and by trabeculectomy alone. $^{8-1021-23}$ The longest follow up period investigated was 12 months, ${ }^{22}$ and all studies looked at the global change in disc parameters.

The clinical significance of these disc changes appears to be unclear, although reports have suggested that there may be an associated improvement of visual function that corresponds to this improvement in disc appearance. ${ }^{5} 10192425$

The purpose of this study was threefold:

- to investigate the evolution of change within the optic disc 2 years after trabeculectomy

- to determine the factors influencing change

- to determine the localisation of change.

\section{Methods}

Patients due to undergo trabeculectomy were recruited from the ongoing Moorfields/ Medical Research Council UK 5-fluorouracil trial currently running at Moorfields Eye Hospital and the Institute of Ophthalmology in London. The project was reviewed and approved by the ethics committee of Moorfields Eye Hospital, and performed in accordance with the 1964 Declaration of Helsinki. Ninety five eyes of 95 patients (mean age 65.1 years; range 45-80) had confocal scanning laser disc imaging with the Heidelberg retina tomograph 4 weeks before surgery (SD 3 weeks), and at 3 months (SD 2 weeks), 1 year (SD 1 month), and 2 years (SD 1 month) after surgery.

The Heidelberg retina tomograph is a confocal scanning diode laser $(670 \mathrm{~nm})$ ophthalmoscope that acquires topographic images of the optic disc and peripapillary retina. The details of the instrument have been described previously ${ }^{26-28}$ and its reproducibility has been established. ${ }^{28-31}$ Disc imaging was performed 
through a pupil dilated with tropicamide $1 \%$ eyedrops, and three images were taken at each imaging session using a 15 degree field of view. Images were inspected for eye movements and the optimum images were saved. The mean topography of three images was used in all analyses using software version 2.01. A contour line was drawn around the optic disc of the preoperative mean topography by the same observer (AK) and this line was exported to the postoperative images using the "export contour line" function that is available with the program. The standard reference plane was used. Keratometry was also performed on these patients preoperatively and postoperatively, and the appropriate reading was entered into the HRT program at each imaging visit.

HRT software analysis version 2.01 has a feature that automatically scales and "magnification corrects" the contour line when it is exported to another mean topography image. However, in order to maintain a quality control over the images used in the analysis, and counter any possible effects of magnification change, mean topography images had to fulfil two criteria. These were:

(1) mean topography standard deviation of less than $40 \mu \mathrm{m}^{32}$

(2) a refractive error change (or change in focus setting) of less than 2 dioptres within the four imaging time points. ${ }^{33}$

If these criteria were not met for any of the images within the four imaging time points, or if the exported contour line did not fit exactly over the optic disc in any image, then the patient data were excluded from the analysis.

The parameters investigated for change following surgery were rim area and rim volume and maximum cup depth. Rim area was defined as the total area within the contour line minus the cup area. Rim volume was defined as the total volume of those parts within the contour line but above the reference plane. The HRT generates a surface other than the reference plane known as the "curved surface." The height of the centre of the curved surface is equal to the mean height of the optic disc margin (as defined by the drawn contour line). Mapping a straight line from this centre to a point on the contour line thus generates the surface itself. The maximum cup depth is therefore defined as the average depth of the $5 \%$ of pixels with the largest depth values within the disc measured from the curved surface. To investigate regional changes, the HRT predefined segments option was used. This divides the disc into six sectors - nasal, superonasal, superotemporal, temporal, inferotemporal, and inferonasal. Optic disc cupping can be of a focal or diffuse variety, and it is possible that segmental changes may not be detectable if the degree of pre-existing disc damage is greater in one segment than another. Therefore, we wished to quantify the depth of pre-existing segmental disc damage. The new HRT software incorporates a Moorfields analysis feature, that has been described in detail elsewhere. ${ }^{34} 35$

Briefly, it gives a predicted value of the global and segmental disc rim area based on the size of the optic disc and a range of normal values. For this study, the predicted rim area in each of the six segments was recorded, and the ratio of the actual rim area to the predicted rim area (for it to be classified as normal) in each segment was calculated. We have termed this ratio "rim index." ${ }^{36}$ If the rim index is a value of 1 or above, the rim area of the disc segment is within the predicted limits for the subjects disc size. If the rim index value is less than 1 , it indicates that the rim area is less than that predicted. The lower the rim index value, the greater the likelihood that the segment has an acquired rim loss. The rim index, therefore, gives a method for determining the degree of pre-existing segmental damage.

Global and segmental change in the optic disc were investigated at three time points-3, 12 , and 24 months after surgery-using the Wilcoxon signed ranks test. A non-parametric test was used as examination of the preoperative disc data showed a skewed distribution.

To determine the possible relation between reversal and other factors besides degree of intraocular pressure reduction, the patients' age and degree of pre-existing glaucomatous damage were recorded. All patients had a 24-2 threshold Humphrey visual field test (Humphrey Instruments) 4 (SD 3) weeks before surgery. We used the average mean deviation of the last two most reliable preoperative fields (reliability indices, $<30 \%$ false positives and negatives, $<25 \%$ fixation losses, and $<2 \mathrm{~dB}$ difference in total mean deviation between the two fields) as a measure of pre-existing disease. Linear regression analysis was used to examine the effect of these three factors on change in rim area, volume, and maximum cup depth.

All analyses were performed using spss version 10 software, and significance was defined as a $p$ value of $<0.001$. A strict $p$ value was chosen to compensate for the multiple significance tests that were being performed to determine localised change.

\section{Results}

The results for 70 eyes were examined. Data were not analysed for 25 patients, because of incomplete imaging data $(n=13)$, refractive error changes of more than 2 dioptres $(n=5)$, and mean topography standard deviations of more than $40 \mu \mathrm{m}(\mathrm{n}=7)$, as defined by the methods section. The average age of the analysed patient group was 65.7 (SD 9.5) years, and preoperative mean deviation was -9.49 (SD 8.41) dB (Table 1).

Intraocular pressure reduced from 22.25 (SD 3.76) $\mathrm{mm} \mathrm{Hg}$, at the time of preoperative imaging, to 15.27 (SD 4.96) $\mathrm{mm} \mathrm{Hg}$ at 3

Table 1 Demographics of study group

\begin{tabular}{lc}
\hline Number of patients & 70 \\
Age & $65.74(9.5)$ \\
Females & 20 \\
POAG & 63 \\
CNAG & 2 \\
PXE glaucoma & 5 \\
Preoperative mean deviation & $9.49(8.41)$ \\
Preoperative IOP & $22.33(3.73)$
\end{tabular}

POAG $=$ primary open angle glaucoma, $\mathrm{CNEG}=$ chronic narrow angle glaucoma, PXE glaucoma $=$ pseudoexfoliative glaucoma. 
Table 2 Change in global disc parameters

\begin{tabular}{lccccc}
\hline & Preop & 3 months & 1 year & 2 years & pat 2 years \\
\hline IOP $(\mathrm{mm} \mathrm{Hg})$ & $22.33(3.73)$ & $15.2(4.96)$ & $14.38(3.89)$ & $13.80(3.54)$ & $<0.001^{\star}$ \\
Rim area $\left(\mathrm{mm}^{2}\right)$ & $0.901(0.349)$ & $0.927(0.350)$ & $0.928(0.361)$ & $0.954(0.382)$ & 0.025 \\
Rim volume $\left(\mathrm{mm}^{3}\right)$ & $0.179(0.109)$ & $0.189(0.115)$ & $0.194(0.125)$ & $0.221(0.137)$ & $<0.001^{\star}$ \\
Maximum cup depth mm & $0.689(0.215)$ & $0.673(0.196)$ & $0.661(0.202)$ & $0.668(0.207)$ & 0.150 \\
\hline
\end{tabular}

Figures are means (SD). Asterisk represents difference significance to predefined level $\mathrm{p}<0.001$ (Wilcoxon ranks test).

Table 3 Change in segmental disc parameters

\begin{tabular}{|c|c|c|c|c|c|c|}
\hline Region & $\begin{array}{l}\text { Preop rim } \\
\text { index }\end{array}$ & $\begin{array}{l}\text { Preop rim area } \\
\left(\mathrm{mm}^{2}\right)\end{array}$ & $\begin{array}{l}3 \text { month rim area } \\
\left(\mathrm{mm}^{2}\right)\end{array}$ & $\begin{array}{l}1 \text { year rim area } \\
\left(\mathrm{mm}^{2}\right)\end{array}$ & $\begin{array}{l}2 \text { year rim area } \\
\left(\mathrm{mm}^{2}\right)\end{array}$ & $\begin{array}{l}p \text { Value at } \\
2 \text { years }\end{array}$ \\
\hline Temporal & 0.55 & $0.127(0.073)$ & $0.131(0.073)$ & $0.128(0.072)$ & $0.133(0.079)$ & 0.258 \\
\hline Superotemporal & 0.53 & $0.097(0.057)$ & $0.103(0.062)$ & $0.104(0.062)$ & $0.105(0.064)$ & 0.007 \\
\hline Inferotemporal & 0.48 & $0.099(0.068)$ & $0.101(0.068)$ & $0.101(0.071)$ & $0.106(0.071)$ & 0.131 \\
\hline Nasal & 0.72 & $0.297(0.119)$ & $0.302(0.116)$ & $0.302(0.118)$ & $0.311(0.122)$ & 0.185 \\
\hline Superonasal & 0.63 & $0.137(0.054)$ & $0.140(0.058)$ & $0.142(0.061)$ & $0.144(0.063)$ & 0.035 \\
\hline Inferonasal & 0.66 & $0.145(0.065)$ & $0.149(0.066)$ & $0.151(0.066)$ & $0.154(0.070)$ & 0.024 \\
\hline Region & $\begin{array}{l}\text { Preop rim } \\
\text { index }\end{array}$ & $\begin{array}{l}\text { Preop rim volume } \\
\left(\mathrm{mm}^{3}\right)\end{array}$ & $\begin{array}{l}3 \text { month rim volume } \\
\left(\mathrm{mm}^{3}\right)\end{array}$ & $\begin{array}{l}1 \text { year rim volume } \\
\left(\mathrm{mm}^{3}\right)\end{array}$ & $\begin{array}{l}2 \text { year rim volume } \\
\left(\mathrm{mm}^{3}\right)\end{array}$ & $\begin{array}{l}p \text { Value at } \\
2 \text { years }\end{array}$ \\
\hline Temporal & 0.55 & $0.009(0.007)$ & $0.010(0.009)$ & $0.010(0.009)$ & $0.013(0.021)$ & 0.218 \\
\hline Superotemporal & 0.53 & $0.018(0.014)$ & $0.020(0.016)$ & $0.021(0.017)$ & $0.024(0.023)$ & 0.002 \\
\hline Inferotemporal & 0.48 & $0.018(0.016)$ & $0.018(0.018)$ & $0.019(0.020)$ & $0.022(0.023)$ & 0.012 \\
\hline Nasal & 0.72 & $0.064(0.044)$ & $0.069(0.047)$ & $0.069(0.049)$ & $0.079(0.053)$ & $<0.001^{\star}$ \\
\hline Superonasal & 0.63 & $0.032(0.019)$ & $0.034(0.020)$ & $0.036(0.022)$ & $0.039(0.025)$ & $<0.001^{\star}$ \\
\hline Inferonasal & 0.66 & $0.037(0.030)$ & $0.039(0.030)$ & $0.040(0.032)$ & $0.045(0.032)$ & 0.002 \\
\hline Region & $\begin{array}{l}\text { Preop rim } \\
\text { index }\end{array}$ & $\begin{array}{l}\text { Preop } \\
\text { max depth cup } \\
(\mathrm{mm})\end{array}$ & $\begin{array}{l}3 \text { month } \\
\text { max depth cup } \\
(\mathrm{mm})\end{array}$ & $\begin{array}{l}1 \text { year } \\
\text { max depth cup } \\
(\mathrm{mm})\end{array}$ & $\begin{array}{l}2 \text { year } \\
\text { max depth cup } \\
(\mathrm{mm})\end{array}$ & $\begin{array}{l}p \text { Value at } \\
2 \text { years }\end{array}$ \\
\hline Temporal & 0.55 & $0.622(0.212)$ & $0.601(0.198)$ & $0.595(0.195)$ & $0.589(0.203)$ & 0.008 \\
\hline Superotemporal & 0.53 & $0.690(0.219)$ & $0.669(0.207)$ & $0.665(0.209)$ & $0.666(0.218)$ & 0.064 \\
\hline Inferotemporal & 0.48 & $0.620(0.213)$ & $0.596(0.195)$ & $0.594(0.193)$ & $0.602(0.205)$ & 0.225 \\
\hline Nasal & 0.72 & $0.611(0.242)$ & $0.599(0.230)$ & $0.574(0.234)$ & $0.575(0.238)$ & 0.011 \\
\hline Superonasal & 0.63 & $0.685(0.230)$ & $0.670(0.220)$ & $0.664(0.229)$ & $0.671(0.237)$ & 0.372 \\
\hline Inferonasal & 0.66 & $0.607(0.225)$ & $0.582(0.210)$ & $0.570(0.207)$ & $0.575(0.211)$ & 0.087 \\
\hline
\end{tabular}

Figures are means (SD). Asterisk represents difference significance to predefined level $\mathrm{p}<0.001$ (Wilcoxon ranks test).

months, 14.38 (SD 3.89) $\mathrm{mm} \mathrm{Hg}$ at 1 year, and 13.80 (SD 3.54) $\mathrm{mm} \mathrm{Hg}$ at 2 years after trabeculectomy. In percentage terms, this represents a reduction of $29.07 \%$ (SD $28.37 \%$ ) at 3 months, $33.71 \%$ (SD $21.03 \%$ ) at 1 year, and $36.62 \%$ (SD $18.64 \%$ ) at 2 years.

GLOBAL ANALYSIS

There was an increase in global rim area (mean $\left(\mathrm{mm}^{2}\right)$ preoperatively 0.901 (SD 0.349); 3 months 0.927 (SD 0.350); 1 year 0.928 (SD $0.361) ; 2$ years 0.954 (SD 0.382)) and global rim volume (mean $\left(\mathrm{mm}^{3}\right)$ preoperatively 0.179 (SD 0.109); 3 months 0.189 (SD 0.115); 1 year 0.194 (SD 0.125); 2 years 0.221 (SD $0.137)$ ) over the 2 year period following trabeculectomy. These changes were only significant at 2 years postoperatively. The maximum depth of the cup decreased at 3 months and 1 year, but showed a slight increase at 2 years, although this was still less than that found at the preoperative imaging session (mean (mm) preoperatively 0.689 (SD 0.215 ); 3 months 0.673 (SD 0.196); 1 year 0.661 (SD 0.202); 2 years 0.668 (SD 0.207)). These changes, however, were not significant (Table 2).

SEGMENTAL ANALYSIS

Rim area increased over the 2 year period, but was not localised to one area. Analysis of rim volume change found that at 2 years, "significant" increases occurred in the nasal $(p<0.001)$ and superonasal $(\mathrm{p}<0.001)$ segments, as well as in the inferonasal $(p=0.002)$ and the superotemporal segment $(\mathrm{p}=0.002)$, although changes in these last two segments did not quite meet our "significance" level criteria. No significant change in rim volume in any segment was found at the earlier two time points. Change in maximum depth was significantly greatest in the nasal region of the disc at year 1 , but this became non-significant by year 2. For the group, the average rim index was smallest in the inferotemporal region, and greatest in the nasal region. This would imply that the region with

Table 4 Linear regression coefficients for factors age, preoperative mean deviation (MD) and change in IOP

At 3 months

\begin{tabular}{lrrr}
\hline Factor & Rim area & Rim volume & Max cup depth \\
\hline Age & -0.068 & -0.126 & -0.022 \\
Preop MD & 0.031 & -0.090 & -0.048 \\
IIOP at 3 months & -0.186 & 0.025 & 0.354
\end{tabular}

\begin{tabular}{llrl}
\hline At 1 year & & & \\
\hline Age & -0.181 & -0.160 & 0.192 \\
Preop MD & -0.035 & 0.010 & -0.021 \\
$\Delta$ IOP at 1 year & $-0.445^{\star}$ & -0.250 & $-0.415^{\star}$ \\
& & & \\
\end{tabular}

\begin{tabular}{lccc}
\hline At 2 years & & & \\
\hline Age & -0.262 & -0.217 & 0.081 \\
Preop MD & 0.014 & 0.060 & -0.105 \\
$\Delta$ IOP at 2 years & $-0.452^{\star}$ & -0.260 & $-0.400^{\star}$
\end{tabular}

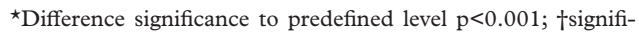
cance at $\mathrm{p}<0.05$ level. 

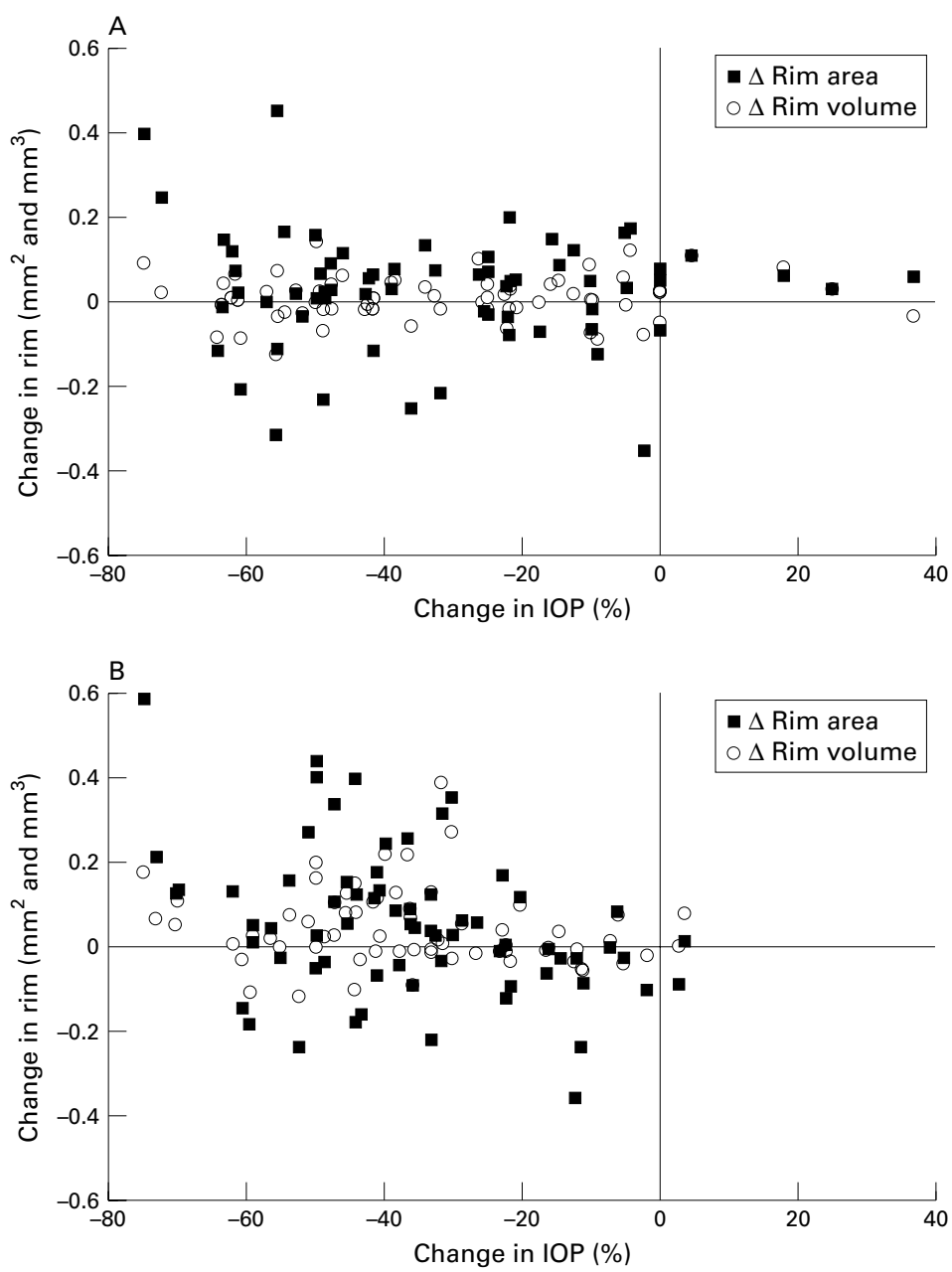

Figure 1 Relation between change in rim parameters and percentage change in intraocular pressure (IOP). (A) At 3 months. Change rim area: $r=-0.186$; change rim volume: $r=0.025$. (B) At 2 years. Change rim area: $r=-0.452$; change rim volume: $r=$ 0.260 . See Table 4. patients, reversal of cupping was present at 2 weeks after surgery, but disappeared by 4 and 8 months postoperatively. Their group of patients had a large reduction in intraocular pressure $(49.3 \%$ (SD $14.9 \%)$ ), and had preoperative rim volume (mean $0.163 \mathrm{~mm}^{3}$ ) that was comparable to our group (mean $0.179 \mathrm{~mm}^{3}$ ). However, the average preoperative mean deviation of their group was 13.2 (SD 6.8) dB, compared with our 9.49 (SD 8.41) dB, suggesting that our group had fewer patients with advanced disease. Experimental studies have shown that the earlier the stage of glaucoma, the more likely reversal of cupping will occur. ${ }^{16}{ }^{17}$ Although linear regression analysis did not find any significant association between degree of pre-existing disease and disc reversal it is possible that our group did not have a wide enough range of pre-existing disease for a relation to be detected.

The overall pressure reduction in our group $(-36.62 \%$ (SD $18.64 \%)$ at 2 years) was not as large as that reported by the previous two groups, but linear regression analysis did show that this was an important factor in determining disc change. This agrees with other studies that have shown that pressure reduction is an important factor in cupping reversal ${ }^{5-7} 1537$ and it has been suggested that a $30 \%$ pressure reduction is necessary before any disc reversal occurs. Both groups mentioned above did not find any significant association between disc reversal and age, as was the same for our group of subjects. However, reports have suggested that the degree of optic nerve head compliance decreases with age, ${ }^{38-41}$ so one could expect age to have a significant effect on the ability of the lamina to move adequately with IOP reduction, which would be indicated by the mean cup depth. A possible reason for our and earlier studies' finding of no such movement is the mean age group of all three studies (Irak et al 70.9 years; Topouzis et al 65 years; our group 65.7 years); if there had been more younger patients in the studies, then such an effect may have been found.

It is believed that the main site of glaucomatous damage is at the lamina cribrosa area, and that raised intraocular pressure causes a bowing back of the lamina, resulting in the damage to the nerve fibre bundles passing through the cribrosal plates. $^{42}{ }^{43}$ It has generally been accepted that one of the main reasons for an apparent improvement in optic nerve appearance with IOP reduction is a reduction in the posterior bowing of the lamina cribrosa, giving relief to these compressed nerve fibre bundles. It has also been shown experimentally that reversal is more likely to occur in early stages of the disease. ${ }^{16}{ }^{17}$ The pattern of optic disc cupping is such that the last area of the disc to be affected is the nasal disc region, and in particular the upper nasal region. ${ }^{45}$ In our group, segmental improvement was localised to the nasal regions, and the rim index value for this group of patients was largest in the nasal segment (0.72), indicating that this segment had the least degree of pre-existing damage. The inferotemporal disc region has been shown to be the site of early glaucomatous damage, ${ }^{44}$ and in our group this region had the 
lowest rim index value (0.48), indicating that this area had a greater degree of pre-existing damage. A possible explanation for the improvement being confined to the nasal disc regions may be because this area was least affected by the disease and so, possibly, nerve fibre bundle compression was not as longstanding or as permanent as that within the inferotemporal disc regions. Therefore, with IOP reduction, and forward shifting of the lamina cribrosa, the nerve fibres within the nasal region may regain their original shape, while those within the inferotemporal disc region may be too damaged to be able to do so.

Significant segmental change in rim volume was detected, and not in rim area. However, inspection of the results (Table 3) shows that a steady increase in rim area was found at all three postoperative time points, having greatest magnitude in the nasal disc regions, but was not statistically significant. The standard deviations of the area measurements were much larger than those found with the volumetric measurements. Segmental rim volume measurements are very small in this group of patients, and so small standard deviations would be expected. This would explain why only change in volume reached statistical significance. However, the clinical significance of such small increases has yet to be determined.

Our study shows that in a large group of moderate to early glaucomatous patients, reduction of intraocular pressure by surgery results in an improvement of the appearance of the optic nerve head, and that this is more obvious in the long term. This may be related to the fact that in our subject group the mean intraocular pressure was at its lowest at the 2 year time point.

It has yet to be determined whether these changes in the appearance of the nerve have any clinical significance. The patients in this study are still being followed up, and investigations are currently under way into whether any true improvement of visual function is associated with these disc changes.

This study was supported by the Medical Research Council grant G9330070, and in part by the International Glaucoma Association.

This work was undertaken by the authors who received a proThis work was undertaken by the authors who received a pro-
portion of funding from the NHS executive. The views portion of funding from the NHS executive. The views
expressed in this publication are those of the authors and not necessarily of the NHS executive.

1 Pederson JE, Herschler J. Reversal of glaucomatous cupping in adults. Arch Ophthalmol 1982;100:426-31.

2 Quigley HA. Childhood glaucoma: results with trabeculotomy and study of reversible cupping. Ophthalmology 1982;89:219-26.

3 Greenidge KC, Spaeth GL, Traverso CE. Change in appearance of the optic disc associated with lowering of intraocular pressure. Ophthalmology 1985;92:897-903.

4 Schwartz B, Takamoto T, Nagin P. Measurements of reversibility of optic disc cupping and pallor in ocular hypertension and glaucoma. Ophthalmology 1985;92:1396407.

5 Katz LJ, Spaeth GL, Cantor LB, et al. Reversible optic disk cupping and visual field improvement in adults with glaucoma. Am $\mathcal{F}$ Ophthalmol 1989;107:485-92.

6 Shin DH, Bielik M, Hong YJ, et al. Reversal of glaucomatous optic disc cupping in adult patients. Arch Ophthalmol 1989;107:1599-603.

7 Rath EZ, Shin DH, Kim C, et al. Relationship between optic disc cupping change and intraocular pressure control in adult glaucoma patients. Graefes Arch Clin Exp Ophthalmol 1996;234:434-9.
8 Irak I, Zangwill L, Garden V, et al. Change in optic disk topography after trabeculectomy. Am F Ophthalmol 1996; 122:690-5.

9 Park KH, Kim DM, Youn DH. Short-term change of optic nerve head topography after trabeculectomy in adult glaucoma patients as measured by Heidelberg retina tomograph. Korean $\mathcal{F}$ Ophthalmol 1997;11:1-6.

10 Lesk MR, Spaeth GL, Azuaro-Blanco A, et al. Reversal of optic disc cupping after glaucoma surgery analyzed with a scanning laser tomograph. Ophthalmology 1999;106:1013-8.

11 Shaffer RN, Hetherington J Jr. The glaucomatous disc in infants. A suggested hypothesis for disc cupping. Trans Am Acad Ophthalmol Otolaryngol 1969;73:923-35.

12 Quigley HA. The pathogenesis of reversible cupping in congenital glaucoma. Am $\mathcal{F}$ Ophthalmol 1977;84:358-70.

13 Robin AL, Quigley HA. Transient reversible cupping in juvenile-onset glaucoma. Am $\mathcal{f}$ Ophthalmol 1979;88(Pt 2):580-4.

14 Spaeth GL, Fernandes E, Hitchings RA. The pathogenesis of transient or permanent improvement in the appearence of the optic disc following glaucoma surgery. In: Greve EL, ed. Glaucoma symposium: diagnosis and therapy. The Hague: De. Glaucoma symposium: diagnosis and therapy. The Hag

15 Shirakashi M, Nanba K, Iwata K. Reversal of cupping in experimental glaucoma. Ophthalmologica 1991;202:194201.

16 Shirakashi M, Nanba K, Iwata K. Changes in reversal of cupping in experimental glaucoma. Longitudinal study. Ophthalmology 1992;99:1104-10.

17 Coleman AL, Quigley HA, Vitale S, et al. Displacement of the optic nerve head by acute changes in intraocular pressure in monkey eyes. Ophthalmology 1991;98:35-40.

18 Burgoyne CF, Quigley HA, Thompson HW, et al. Measurement of optic disc compliance by digitized image analysis in the normal monkey eye. Ophthalmology 1995;102:1790in the

19 Tsai CS, Shin DH, Wan JY, et al. Visual field global indices in patients with reversal of glaucomatous cupping after intraocular pressure reduction. Ophthalmology 1991;98: 1412-9.

20 Azuara-Blanco A, Spaeth GL. Methods to objectify reversibility of glaucomatous cupping. Curr Opin Ophthalmol 1997;8:50-4.

21 Sogano S, Tomita G, Kitazawa Y. Changes in retinal nerve fiber layer thickness after reduction of intraocular pressure in chronic open-angle glaucoma. Ophthalmology 1993;100: in chronic

22 Raitta C, Tomita G, Vesti E, et al. Optic disc topography before and after trabeculectomy in advanced glaucoma. Ophthalmic Surg Lasers 1996;27:349-54.

23 Topouzis F, Peng F, Kotas-Neumann R, et al. Longitudinal changes in optic disc topography of adult patients after trabeculectomy. Ophthalmology 1999;106:1147-51.

24 Spaeth GL. The effect of change in intraocular pressure on the natural history of glaucoma: lowering intraocular pressure in glaucoma can result in improvement of visual fields. Trans Ophthalmol Soc UK 1985;104(Pt 3):256-64.

25 Yildirim E, Bilge AH, Ilker S. Improvement of visual field following trabeculectomy for open angle glaucoma. Eye 1990;4(Pt 1):103-6.

26 Zinser G, Harbarth U, Schroder H. Formation and analysis of three-dimensional data with the laser tomographic Scanner (LTS). In: Nasemann JE, Burk ROW, eds. Scanning laser ophthalmoscopy and tomography. Munich: Quintessenz, 1990.

27 Cioffi GA, Robin AL, Eastman RD, et al. Confocal laser scanning ophthalmoscope. Reproducibility of optic nerve head topographic measurements with the confocal laser scanning ophthalmoscope. Ophthalmology 1993;100:57-62.

28 Rohrschneider K, Burk RO, Kruse FE, et al. Reproducibility of the optic nerve head topography with a new laser tomo-
graphic scanning device. Ophthalmology 1994;101:1044-9.

29 Rohrschneider K, Burk RO, Volcker HE. Reproducibility of topometric data acquisition in normal and glaucomatous topometric data acquisition in normal and glaucomatous optic nerve heads with the laser tomographic sca
Graefes Arch Clin Exp Ophthalmol 1993;231:457-64.

30 Dreher AW, Tso PC, Weinreb RN. Reproducibility of topographic measurements of the normal and glaucomatous optic nerve head with the laser tomographic scanner. Am $\mathcal{F}$ Ophthalmol 1991;111:221-9.

31 Chauhan BC, LeBlanc RP, McCormick TA, et al. Test-retest variability of topographic measurements with confocal scanning laser tomography in patients with glaucoma and control subjects. Am $\mathcal{F}$ Ophthalmol 1994;118:9-15.

32 Kamal DS, Viswanathan AC, Garway-Heath DF, et al. Detection of optic disc change with the Heidelberg retina tomograph before confirmed visual field change in ocular hypertensives converting to early glaucoma. Br f Ophthalhypertensives conver

33 Hosking SL, Flanagan JG. Prospective study design for the Heidelberg retina tomograph: the effect of change in focus setting. Graefes Arch Clin Exp Ophthalmol 1996;234:306-10.

34 Wollstein G, Garway-Heath DF, Hitchings RA. Identification of early glaucoma cases with the scanning laser ophthalmoscope. Ophthalmology 1998;105:1557-63.

35 Uchida H, Kitazawa Y, Tomita G, et al. Diagnostic ability of a new glaucoma classification program of Heidelberg Retina Tomograph II for early glaucoma. IOVS: Suppl 2000;41(4)

36 Kotecha A, Khaw PT, Hitchings RA, et al. In vivo imaging of the lamina cribrosa and its relationship to optic nerve head topography. IOVS: Suppl, 2000;41(4). 
$37 \mathrm{Xu} \mathrm{L}$, Liu L, Yang H, et al. Characteristics of reversal optic cupping in adults glaucoma after reduction of intraocular pressure. Yen Ko Hsueh Pao 1995;11:155-60.

38 Hernandez MR, Luo XX, Andrzejewska W, et al. Agerelated changes in the extracellular matrix of the human optic nerve head. Am f Ophthalmol 1989;107:476-84.

39 Burgoyne CF, Quigley HA, Thompson HW, et al. Early changes in optic disc compliance and surface position in experimental glaucoma. Ophthalmology 1995;102:1800-9

40 Burgoyne CF, Varma R, Quigley HA, et al. Global and regional detection of induced optic disc change by digitized image analysis. Arch Ophthalmol 1994;112:261-8.

41 Albon J, Purslow PP, Karwatowski WS, et al. Age related compliance of the lamina cribrosa in human eyes. $\mathrm{Br}$ Ophthalmol 2000;84:318-23.
42 Emery JM, Landis D, Paton D, et al. The lamina cribrosa in normal and glaucomatous human eyes. Trans Am Acad Ophthalmol Otolaryngol 1974;78:290-7.

43 Quigley HA, Addicks EM, Green WR, et al. Optic nerve damage in human glaucoma. II. The site of injury and susceptibility to damage. Arch Ophthalmol 1981;99:63549.

44 Jonas JB, Gusek GC, Naumann GO. Optic disc morphometry in chronic primary open-angle glaucoma. I. Morphometric intrapapillary characteristics. Graefes Arch Clin Exp Ophthalmol 1988;226:522-30.

45 Airaksinen PJ, Tuulonen A, Alanko HI. Rate and pattern of neuroretinal rim area decrease in ocular hypertension and glaucoma. Arch Ophthalmol 1992;110:206-10.

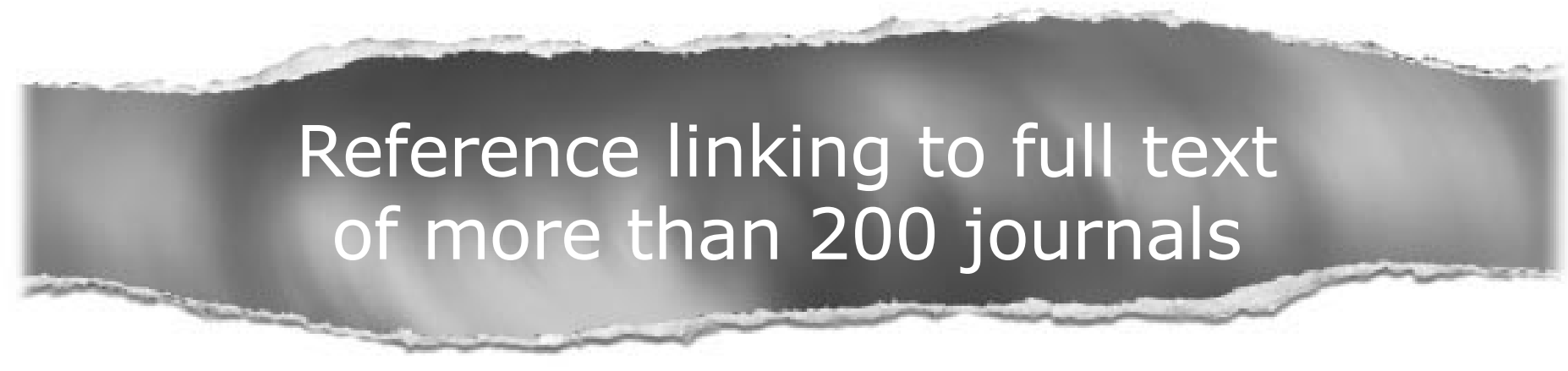

Toll free links

You can access the FULL TEXT of articles cited in the British Journal of Ophthalmology online if the citation is to one of the more than 200 journals hosted by HighWire (http://highwire.stanford.edu) without a subscription to that journal.

There are also direct links from references to the Medline abstract for other titles.

www.bjophthalmol.com 